\title{
L'éducation physique belge, entre atouts et besoin de progrès : terrain d'investigation pour les chercheurs
}

\section{Ghislain Carlier}

\section{OpenEdition}

\section{Journals}

Édition électronique

URL : http://journals.openedition.org/trema/2498

DOI : $10.4000 /$ trema.2498

ISSN : 2107-0997

Éditeur

Faculté d'Éducation de l'université de Montpellier

Édition imprimée

Date de publication : 24 octobre 1997

Pagination : 107-119

ISSN : 1167-315X

Référence électronique

Ghislain Carlier, «L'éducation physique belge, entre atouts et besoin de progrès : terrain d'investigation pour les chercheurs », Tréma [En ligne], Hors série N¹ | 1997, mis en ligne le 03 janvier 2011, consulté le 21 avril 2019. URL : http://journals.openedition.org/trema/2498 ; DOI : 10.4000/trema.2498

Ce document a été généré automatiquement le 21 avril 2019

Trema 


\title{
L'éducation physique belge, entre atouts et besoin de progrès : terrain d'investigation pour les chercheurs
}

\author{
Ghislain Carlier
}

\section{RÉSUMÉS}

L'analyse de la situation de l'éducation physique dans l'enseignement libre en Belgique permet de tenter de formuler ce que pourrait être une véritable culture corporelle. L'action de l'E.D.P.M. (unité de recherche «éducation par le mouvement ») dans le cadre de la formation continue est décrite comme permettant une amélioration sensible de la situation de l'éducation physique.

This analysis of the place of PE in the private school (mostly catholic) teaching system in Belgium enables us to attempt to establish what a true body culture could be. The activity of the EDPM (an "education through movement" research unit) within the framework of teacher continuing education is described as allowing a real improvement in the position of PE.

\section{INDEX}

Mots-clés : Belgique, éducation physique, formation, recherche

Keywords : Belgium, instruction, physical education, research 


\section{AUTEUR}

\section{GHISLAIN CARLIER}

Institut d'éducation physique et de réadaptation, université catholique de Louvain, Belgique 